\title{
OPEN Assessment of genetic variability in captive capuchin monkeys (Primates: Cebidae)
}

\author{
Mariela Nieves ${ }^{1,2 凶}$, María Isabel Remis ${ }^{2,3}$, Carla Sesarini ${ }^{1}$, Diana Lucrecia Hassel ${ }^{4}$, \\ Carina Francisca Argüelles ${ }^{4}$ \& Marta Dolores Mudry ${ }^{1,2}$
}

Capuchin monkeys (genera Cebus and Sapajus) show a wide range distribution, from Honduras to Argentina. The aim of this work was to evaluate the genetic and phenotypic variability of captive specimens putatively belonging to S. cay (SCY) and S. nigritus (SNI) at their southernmost distribution limit. Forty-four individuals held in five captive centers from Argentina were analyzed based on external morphology, karyology and DNA sequences of mitochondrial control region (mtDNA-CR). Three morphotypes associated with their probable geographical origin in SCY and a single morphotype in SNI were found. For SCY we could associate each morphotype with the most frequent karyotype. SNI showed a single phenotype and a homogenous karyotype. Heterochromatin showed geographical patterns within species. A 515-bp mtDNA-CR fragment was sequenced, defining fourteen haplotypes at 59 polymorphic sites. A network constructed with our 14 haplotypes and other 77 from S. apella, S. macrocephalus, S. cay and S. nigritus from bibliography revealed some phylogeographic signals. Our SCY and SNI samples rendered four groups that differed in multiple mutational steps, with SCY being more similar to S. apella than to S. macrocephalus. Also, we identified two genetic divergent SCY groups: samples from NOA and from NEA with high mitochondrial diversity. Our results highlight the relevance of using complementary genetic tools throughout the distribution ranges of SCY and SNI for a better assessment of their diversity.

Capuchin monkeys, also known as caiararas or macacos-prego, are among the most widely distributed Neotropical primates (Platyrrhini). They inhabit almost all forested areas from Honduras and Nicaragua in Central America to the Argentinean provinces of Misiones, Salta, Jujuy, Formosa and Chaco in South America ${ }^{1-3}$. Capuchins display a remarkable diversity across their distribution range in terms of ecological, morphological, phenotypical (particularly the coat color), behavioral and genetic features at both inter- and intra-population levels. As a result, the taxonomy of this group has been repeatedly revised ${ }^{4-9}$.

Currently, capuchin monkeys are assigned to genera Cebus and Sapajus (gracile and robust capuchins, respectively $)^{10,11}$. The species studied in the present work, Cebus cay and Cebus nigritus, were transferred to Sapajus by Lynch Alfaro et al. ${ }^{11}$. However, numerous studies on the taxonomy, evolutionary cytogenetics and molecular genetics of capuchins conducted over the last 40 years support the original classification of these monkeys into a single genus ${ }^{12-19}$. Notwithstanding this, in the present study we adopted the current taxonomic classification of this group to prevent misinterpretations of the results and to allow us to use available information on genetic variability.

According to Rimoli et al. ${ }^{20}$, Sapajus cay (SCY) is resident and native in Brazil, Bolivia, Paraguay and Argentina. In Brazil can be found in the states of Mato Grosso and Mato Grosso do Sul (south, east, west and southwest). In Paraguay, S. cay occurs to the east of the Paraguay River and the distribution extends southward to

\footnotetext{
${ }^{1}$ Grupo de Investigación en Biología Evolutiva (GIBE), Departamento de Ecología, Genética y Evolución (DEGE), Facultad de Ciencias Exactas y Naturales, Universidad de Buenos Aires, Intendente Güiraldes 2160, C.A.B.A., C1428EGA Buenos Aires, Argentina. 'Instituto de Ecología, Genética y Evolución de Buenos Aires (IEGEBA), CONICET-Universidad de Buenos Aires, Intendente Güiraldes 2160, C.A.B.A., C1428EGA Buenos Aires, Argentina. ${ }^{3}$ Genética de la Estructura Poblacional (GEP), Departamento de Ecología, Genética y Evolución (DEGE), Facultad de Ciencias Exactas y Naturales, Universidad de Buenos Aires, Intendente Güiraldes 2160, C.A.B.A., C1428EGA Buenos Aires, Argentina. ${ }^{4}$ Grupo de Investigación en Genética Aplicada (GIGA), Departamento de Genética, Facultad de Ciencias Exactas, Químicas y Naturales. Instituto de Biología Subtropical (IBS)- Nodo Posadas, Consejo Nacional de Investigaciones Científicas y Técnicas (CONICET), Universidad Nacional de Misiones (UNaM), Jujuy 1745, 3300 Posadas, Misiones, Argentina. ${ }^{\bowtie}$ email: mariela.nieves5@gmail.com
} 


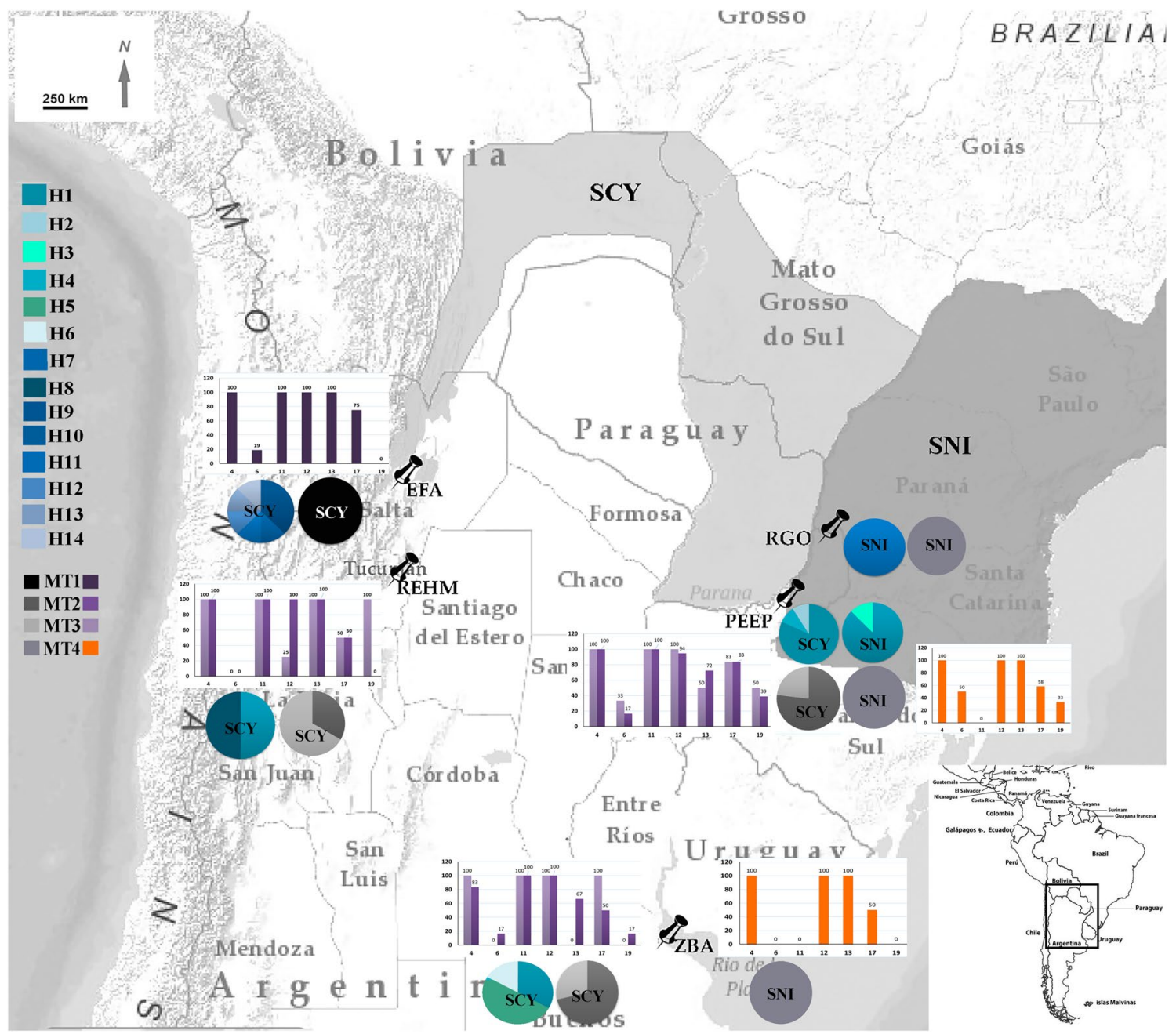

Figure 1. Map illustrating the southernmost natural distribution of capuchin monkeys in South America and location of the different Argentinian centers where samples were obtained. Modified from ${ }^{59,60}$ and UICN species distribution maps. EFA Estación de Fauna Autóctona (Salta), REHM Reserva Experimental Horco Molle (Tucumán), ZBA Zoológico de Buenos Aires, PEEP Parque Ecológico El Puma, RGO Reserva Güira Oga, SCY Sapajus cay, SNI Sapajus nigritus. Percent of heterochromatic blocks in different polymorphic chromosome pairs of each center are shown in bar diagram (purple scale and orange represent the chromosomal frequencies of each morphotype). Haplotype (H_) and morphotype (MT) frequencies in each center are shown in the pie charts and their size is proportional to sample size. The haplotypes and morphotypes are color-coded.

the eastern part of the country, reaching into northwestern Argentina. It also occurs in southeast Bolivia, and northern Argentina (provinces of Jujuy, Salta, Formosa and Chaco). The distribution of S. cay forms a horse shoe shape, bordering the xerophytic Chaco of Argentina, Bolivia and Paraguay. In these countries, the species' geographic limits are the Andes Mountains of Argentina and Bolivia to the west and the east of the Paraguay River, in Paraguay to the east; the confluence of the Paraguay and Parana Rivers might represent its southeasternmost limit ${ }^{20}$. Sapajus nigritus (SNI) occurs south of the Rio Doce, in the Brazilian states of Minas Gerais (south of the Doce River), São Paulo, Paraná, Santa Catarina and Rio Grande do Sul. In Argentina it is found at the northernmost tip of the Argentine province of Misiones (east of the Paraná River). The limits are the Doce River in the north, the State of Rio Grande do Sul in the south (that is not defined yet), the Atlantic Ocean in the east and the province of Misiones in Argentina in the west ${ }^{21}$. Lynch-Alfaro et al. ${ }^{22}$ suggests the presence of two S. nigritus subspecies: S. n. cucullatus in Santa Catarina and Rio Grande do Sul (Brazil), and Iguazú (Argentina); and S. n. nigritus in Minas Gerais, Espírito Santo, São Paulo and Rio de Janeiro (Brazil). The provinces of Salta and Chaco in northern Argentina and northern Rio Grande do Sul state in Brazil represent the southernmost distribution limit for SCY and SNI (Fig. 1).

Capuchin monkeys have particular genomic and chromosomal features: a conserved karyotype compared with that of the ancestral Neotropical primate, the largest amount of genetic information at the euchromatin level shared with humans, and large and conspicuous heterochromatic regions distributed throughout the karyotype. In capuchins, extracentromeric heterochromatin is genus-specific and shows intraspecific and interspecific variability. This makes the heterochromatin pattern a suitable marker for taxonomic identification, particularly for specimens of unknown geographical origin ${ }^{19,23-26}$. 
Both species exhibit phenotypic variations mainly in coat and face coloration ${ }^{1}$. They are phylogenetically close species well suited to illustrate the most outstanding feature of capuchins' genome, namely, the great variability in the amount and distribution of extracentromeric heterochromatin. Particularly, SCY has an extracentromeric heterochromatin block representing $75 \%$ of the $\mathrm{q}$ arm in chromosome 11 , which is absent in $\mathrm{SNI}^{27,28}$.

Molecular genetic studies on arboreal primates have received increasing attention in the last years. Approaches using nuclear genetic markers and/or mitochondrial DNA sequences have contributed greatly to our understanding of phylogenetic, phylogeographic and biogeographic relationships among Neotropical primates ${ }^{17,29-34}$. Several studies addressing the spatial distribution of genetic lineages of the same or closely related species have focused on the analysis of the non-coding control region of the mitochondrial DNA (mtDNA-CR) or D-loop due to its high substitution rate and polymorphisms concentrated in the hypervariable region ${ }^{35,36}$. In particular, mtDNA-CR sequences from SCY and SNI have been examined to infer molecular phylogenies of capuchins or to identify Sapajus matrilineal haplotypes ${ }^{32,33}$.

Despite major advances in our knowledge of genomics of capuchin monkeys during the last decade, relevant information is still missing due to gaps in sampling. This is the case for their geographic distribution area in Argentina.

This study presents a holistic analysis of phenotypic, karyotypic and mtDNA-CR variation in 44 specimens belonging to two putative species of Sapajus, some of them with unknown provenance, housed at five centers in Argentina. The current study constitutes the first mtDNA-CR description in specimens from Argentina, the southernmost distribution limit of the genus. Chromosomal and phenotypic variability is analyzed considering new samples and approaches extending the findings from previous works ${ }^{19,37}$. It is also examined the contribution of the results here presented together with published information about wild and captive individuals of known species and origin can help understand the data from the uncertain provenance of captive individuals. Our results are expected to contribute to come up with a better understanding of the diversity and evolution of capuchin monkeys.

\section{Results}

Genetic and phenotypic variability of captive specimens of robust capuchin monkeys putatively belonging to Sapajus cay (SCY) and Sapajus nigritus (SNI) were evaluated. Forty-four individuals held in five captive centers in Argentina were studied based on external morphology, karyology, and DNA sequences of the mitochondrial control region (mtDNA-CR) (Fig. 1; Table 1). The individuals were classified into four morphotypes (MT), based on external characteristics. Three of these (MT 1, 2 and 3) corresponded to SCY and the remaining one (MT 4) to SNI. A summarized description is provided as follows:

Morphotype 1 (MT 1; Figs. 1, 2a): it had a yellowish-white head, with black forehead and temples. The belly and chest were grayish or light brown, contrasting with the black crown and sideburns. There was a prominent dark dorsal stripe. The limbs were mainly dark brown to blackish and the upper arms were not lighter than the body. Individuals grouped in MT 1 were \#773, 775, 776, 777, 779, 780, 781, 782, 783 and 784 from Estación de Fauna Autóctona (EFA), Salta.

Morphotype 2 (MT 2; Figs. 1, 2b): The belly, chest, back and upper third of the arms were light yellow. Tail, limbs and back of head were dark brown. Shoulders were lighter than the rest of the body. Individuals grouped in MT 2 were \#634, 737, 738, 739, 740 from Zoológico de Buenos Aires (ZBA), Buenos Aires; \#675, 676, 706, 708, 709, 710, 711, 729, 730, 736 from Parque Ecológico El Puma (PEEP), Misiones and \#765 from Reserva Experimental Horco Molle (REHM), Tucumán.

Morphotype 3 (MT 3; Figs. 1, 2c): The belly and chest were light brown. The back, limbs and tail were dark brown; the top of the head and crests were blackish. Individuals grouped in MT 3 were \#733 and 741 from ZBA, Buenos Aires; \#674, 698 and 699 from PEEP, Misiones and \#763 and 764 from REHM, Tucumán.

Morphotype 4 (MT 4, Figs. 1, 2d): The coat varied from dark brown to blackish over the body, with no (or very vague) dorsal stripe. Its face was whitish and had inconspicuous sideburns. The limbs were darker than the body, usually blackish. Pointed crown tufts in adults, if present, wear away with age. The individuals grouped in MT 4 were \#677, 687, 696, 697, 707, 712, 734 and 735 from PEEP, Misiones, \#760 from RGO, Misiones and $\# 732$ from ZBA, Buenos Aires.

Karyological diagnosis confirmed the taxonomic status in $77.27 \%$ (34/44) of the specimens studied, of which 27 were assigned to SCY and 7 to SNI. In the remaining 10 individuals, lymphocyte culture yielded non-evaluable results (Table 2). We were able to discriminate between polymorphisms for $\mathrm{C}+$ band (i.e., absence/presence of a $\mathrm{C}+$ band or differences in block size) and polymorphisms for structural rearrangements involving $\mathrm{C}+\mathrm{bands}$. All the individuals showed the centromeric heterochromatic band in the entire complement. Blocks of pairs \#4, 11 and 12 were present in almost all metaphases from SCY individuals, while the block of pair \#11 was absent in all SNI individuals. Figure 3 shows a typical G-band (Fig. 3a,b) and heterochromatin patterns of both species including examples of heterochromatic polymorphisms observed. In addition, Fig. 1 illustrates for most centers sampled, bar diagrams with frequencies of different $\mathrm{C}+$ bands in each chromosomal pair with extracentromeric heterochromatin. In both species, chromosomal pairs \#6, 13, 17 and 19 were polymorphic for the presence of $\mathrm{C}+$ bands detected in homozygous and heterozygous condition. Pair \#19 was the most polymorphic for both species. In SNI (Fig. 3c), the C + band was absent in one of the homologues of 4/7 (57.2\%) individuals and in both homologues of 3/7 (42.8\%) individuals, while in SCY, the C+ band lacked in one of the homologues of 3/27 (11.11\%) specimens and in both homologues of 16/27 (59.3\%) specimens. Chromosomal pair \#17 was the second most polymorphic for SNI individuals, of which 5/7 (71.4\%) lacked the C+ band in one of the homologues and $1 / 7(14.3 \%)$ in both of them. For SCY, the second most polymorphic pair was \#6, with 3/27 (11.11\%) individuals 


\begin{tabular}{|c|c|c|c|}
\hline \multirow[b]{2}{*}{ Institution } & \multirow[b]{2}{*}{ Collection number (\$) } & \multicolumn{2}{|l|}{ Provenance $(\infty)$} \\
\hline & & Known & Unknown \\
\hline \multirow{2}{*}{ Parque Ecológico "El Puma" (PEEP) } & \begin{tabular}{|l|} 
SCY \\
$674-676,698,699,706,708-711,729,730$, \\
${ }^{*} 736$
\end{tabular} & $\begin{array}{l}\text { Carmen del Paraná, Paraguay (708); Garupá, } \\
\text { Misiones }(710,711)\end{array}$ & $674-676,698,699,706,709,729,730$ \\
\hline & \begin{tabular}{|l|} 
SNI \\
$677,687,696,697, * 707,712,734,735$
\end{tabular} & $\begin{array}{l}\text { Oberá, Misiones (677, 712); Cruce Caballero, } \\
\text { Misiones (687); Montecarlo, Misiones (696) }\end{array}$ & $697,734,735$ \\
\hline Reserva Privada Güira Oga $(\mathrm{RGO})^{\mathrm{b}}$ & $\begin{array}{l}\text { SNI } \\
760\end{array}$ & Puerto Iguazú, Misiones & \\
\hline Reserva Experimental Horco Molle (REHM) ${ }^{c}$ & \begin{tabular}{|l|l|} 
SCY \\
$763-765$
\end{tabular} & & $763-765$ \\
\hline \multirow{2}{*}{ Zoológico de Buenos Aires (ZBA) ${ }^{\mathrm{d}}$} & \begin{tabular}{|l|l|} 
SCY \\
$414,634,733,737, * 738,739,740,741$
\end{tabular} & & $414,634,733,737,739-741$ \\
\hline & $\begin{array}{l}\text { SNI } \\
732\end{array}$ & & 732 \\
\hline Estación de Fauna Autóctona (EFA) & \begin{tabular}{|l} 
SCY \\
$773,775,776,777,779,780,781,782,783$ \\
784
\end{tabular} & $\begin{array}{l}\text { Bolivia (773); Orán, Salta (775, 776, 781); } \\
\text { Güemes, Salta (777); J.V. González, Salta } \\
\text { (779); Aguaray, Salta (780); El Quebrachal, } \\
\text { Salta (783) }\end{array}$ & 782,784 \\
\hline Total & 44 & & \\
\hline
\end{tabular}

Table 1. Summary of the 44 analyzed Sapajus individuals kept in captivity in different Argentinean centers.

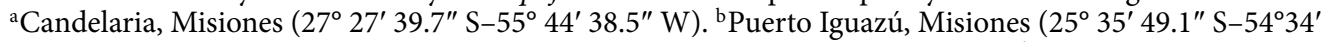
43.1" W). 'San Miguel de Tucumán, Tucumán ( $\left.26^{\circ} 48^{\prime} 32.1^{\prime \prime} \mathrm{S}-65^{\circ} 13^{\prime} 14.8^{\prime \prime} \mathrm{W}\right)$. ${ }^{\mathrm{d}}$ Ciudad Autónoma de

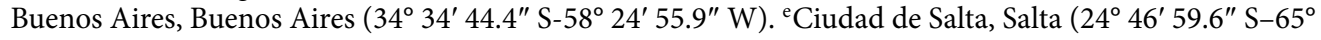
$\left.24^{\prime} 41.7^{\prime \prime} \mathrm{W}\right)$. ( $\$$ ) Corresponds to the collection of our research group: Grupo de Investigación en Biología Evolutiva (GIBE). $(\infty)$ Origin of the individual regardless of whether or not the referred locality corresponds to the natural distribution of the species. ${ }^{*}$ Captive-born individuals.

lacking the $\mathrm{C}+$ band in one homologue or showing C-band size heteromorphism, and 17/27 (62.96\%) specimens without the $\mathrm{C}+$ band in both homologues. In regard to the chromosomal pair \#13, in SCY, absence of $\mathrm{C}+$ band in one homologue and $\mathrm{C}+$ band size heteromorphism were found in $7 / 27$ individuals (25.92\%) (Fig. 3e), while there was no $\mathrm{C}+$ band in either homologue in $4 / 27$ (14.81\%) individuals (Fig. 3f). In addition, one SCY individual showed a paracentric inversion resulting in two $\mathrm{C}+$ bands (Fig. $3 \mathrm{~g}$, see arrows) and 2 SNI individuals showed additional C + bands in chromosomal pairs \#12 and 13 (Fig. 3d, see arrows).

The mtDNA-CR analysis indicated that the designed specific primers allowed the successful amplification of a $515 \mathrm{bp}$ fragment for each of the 44 specimens analyzed. A total of 37 (84\%) good-quality individual sequences ( 9 for SNI and 28 for SCY) were obtained, used in subsequent analyses and submitted to GenBank (KJ737380KJ737416). The absence of nuclear mitochondrial DNA segments was confirmed by the presence of single bands in PCR amplifications and single peaks in mtDNA-CR sequences. One sample from ZBA (\#738) was excluded from the variability analysis because it belonged to an offspring of specimen $\# 740$. When considering both species; we identified 14 haplotypes defined by 59 variable sites. We detected 40 transitions and 1 transversion in SCY, and 33 transitions and 2 transversions in SNI (Table S1). Haplotype 1 (H_1) was the most frequent in both species and the only haplotype shared between them. The remaining haplotypes were similar in frequency; two of them were only detected in SNI whereas 11 haplotypes were only identified in SCY (Tables 2, 3). Substantial variation was found within SCY, with a large number (9/12) of unique haplotypes. According to these results, SCY showed higher levels of genetic diversity—as evaluated by haplotype diversity $(h)$ and nucleotide diversity $(\pi)$-compared with SNI (Table 3 ). Within SCY, the morphotype 1 with the highest haplotype diversity and moderate nucleotide diversity was detected in EFA indicating a high number of closely related haplotypes in Salta (NOA). Both morphotype 3 with highest nucleotide diversity or morphotype 2 with the lowest genetic indices were found in both NOA and NEA regions.

We also included mtDNA-CR reference sequences of SCY, SNI, S. apella (SAP) and S. macrocephalus (SMA) (two nearby species) from GenBank (see details in Material and Methods section) for a more comprehensive genetic diversity analysis of the species analyzed here at their southernmost distribution limit. Three of the four SCY reference sequences from Brazil and Paraguay matched H_1, while the remaining one correlated with a haplotype that could not be attributed to any of the species under study (identified as HC). The analysis of the six reference sequences of SNI revealed five different haplotypes, which were not shared with the species analyzed here (identified as HN1, HN2, HN3, HN4 and HN5). The examination of twenty-six sequences of SMA identified twenty-four haplotypes whereas the study of sixty-three sequences of SAP distinguished forty-eight haplotypes. Only one reference sequence of SMA matched with the H_5 detected in SCY in the present paper.

In general, the median-joining network constructed using both haplotypes identified here and those from reference samples clustered the Sapajus haplotypes according to the putative species (Fig. 4). SCY and SNI haplotypes were included in four groups that differed in multiple mutational steps. One of them (Group A) included the most frequent haplotype (H_1), from which derived two singly occurring haplotypes unique to SCY housed in PEEP (H_2, H_4) and one singly occurring haplotype unique to SNI housed in RGO (H_7) as well as one previously detected haplotype in SCY from Mato Grosso, Brazil (HC1). Two groups (Groups B and C) included only haplotypes detected in SCY. Group B comprised the H_9 from which four closely related singletons housed in EFA and REHM (H_8, H_10, H_12, H_13) emerged. Group C included related haplotypes housed in ZBA 

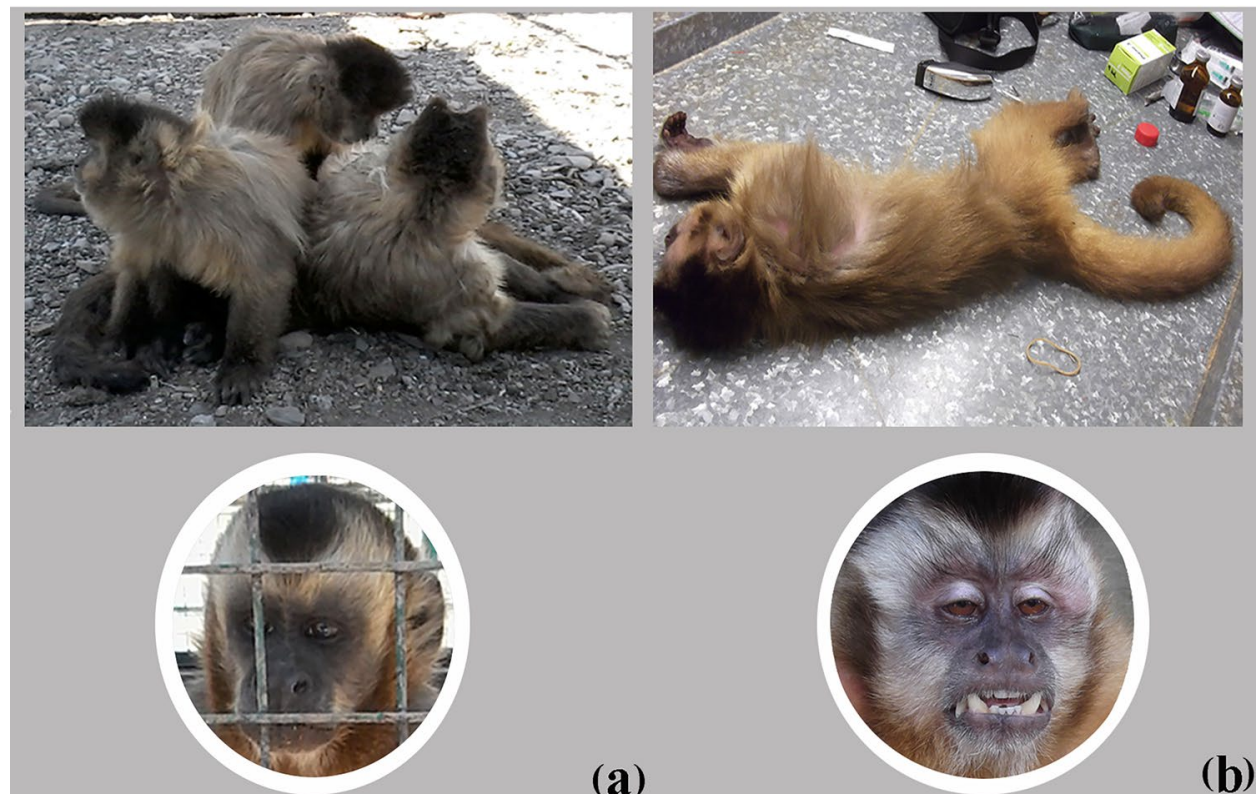

(a)

(b)
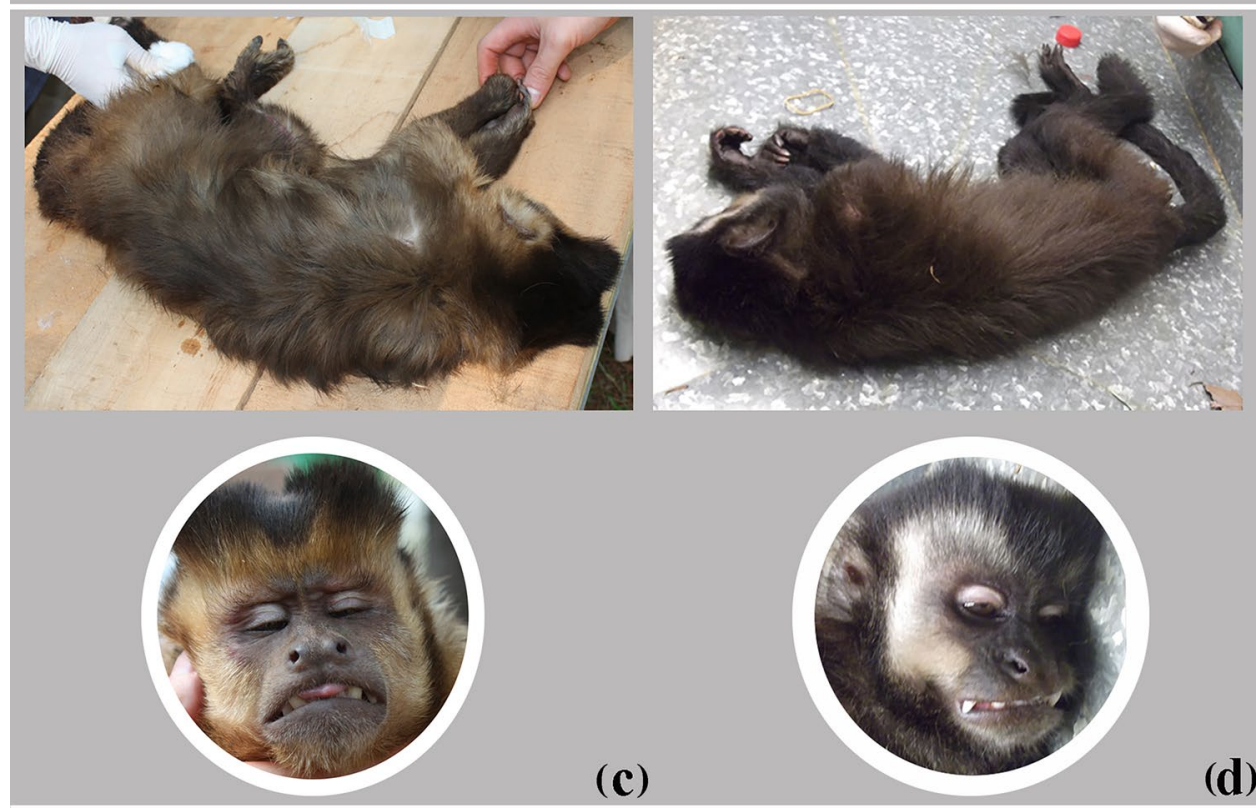

Figure 2. Typical phenotypes of the studied individuals. SCY Morphotype 1 (a). SCY Morphotype 2 (b). SCY Morphotype 3 (c). SNI Morphotype 4 (d). Photographs by M. Nieves.

and EFA (H_6, H_11, H_14). As a general factor, SCY haplotypes identified in the present paper were more similar to SAP than to SMA haplotypes, indeed, some haplotypes for NOA (H6 H11 H14) were most like SAP haplotypes from south Brazil.

The remaining group (Group D), different from any other haplotype group, included related haplotypes of SNI: H_3 haplotype detected in the present contribution and four related haplotypes (HN2, HN3, HN4, HN5) detected in reference samples from southern Brazil and Northern Argentina. Finally, two haplotypes identified here were distant from the other ones. One of them, H_5 belonging to 2 SCY specimens from ZBA matched to a SMA reference sequence. From it emerge some others SMA haplotypes in the network. The other one, HN1 corresponding to a SNI sample reference, clustered with SAP haplotypes from which diverged in many mutational steps.

\section{Discussion}

Over the last years, the diversification and radiation of capuchin monkeys have been analyzed and different biogeographical hypothesis were tested. However, the results of these studies were obtained only with molecular datasets, with less attention paid to karyotype and morphological variation. This is particularly certain for the two species studied herein, which were transferred to Sapajus and are located at the southernmost distribution 


\begin{tabular}{|c|c|c|c|c|c|c|c|c|c|c|c|c|c|c|}
\hline \multirow[b]{3}{*}{ Species } & \multirow{3}{*}{$\begin{array}{l}\text { Morphotype } \\
\text { (MT) }\end{array}$} & \multirow[b]{3}{*}{ Institution } & \multirow{3}{*}{$\begin{array}{l}\text { Collection } \\
\text { number }\end{array}$} & \multicolumn{10}{|c|}{ Cytogenetic studies } & \multirow{3}{*}{\begin{tabular}{|l}
$\begin{array}{l}\text { Molecular } \\
\text { studies }\end{array}$ \\
mtDNA-CR \\
Haplotype ID
\end{tabular}} \\
\hline & & & & \multirow[b]{2}{*}{ BG } & \multicolumn{8}{|l|}{ BC } & \multirow[b]{2}{*}{ Observations } & \\
\hline & & & & & $\mathrm{C}+$ & 4 & 6 & 11 & 12 & 13 & 17 & 19 & & \\
\hline SCY & MT 1 & EFA & 773 & $\sqrt{ }$ & ++ & ++ & +- & ++ & ++ & ++ & +- & -- & & H_9 \\
\hline SCY & MT 1 & EFA & 776 & $\sqrt{ }$ & ++ & ++ & -- & ++ & ++ & ++ & ++ & -- & & H_10 \\
\hline SCY & MT 1 & EFA & 779 & $\sqrt{ }$ & ++ & ++ & -- & ++ & ++ & ++ & +- & -- & & H_9 \\
\hline SCY & MT 1 & EFA & $781 ¥$ & \multicolumn{10}{|l|}{ NA } & H_12 \\
\hline SCY & MT 1 & EFA & 782 & $\sqrt{ }$ & ++ & ++ & -- & ++ & ++ & ++ & ++ & -- & & H_13 \\
\hline SCY & MT 1 & EFA & $784 ¥$ & \multicolumn{10}{|l|}{ NA } & H_9 \\
\hline SCY & MT 1 & EFA & 780 & $\sqrt{ }$ & ++ & ++ & -- & ++ & ++ & ++ & ++ & -- & & H_11 \\
\hline SCY & MT 1 & EFA & 783 & $\sqrt{ }$ & ++ & ++ & ++ & ++ & ++ & $\mathrm{p}^{* *}$ & ++ & -- & ${ }^{* *} \mathrm{~Pa} . \mathrm{Inv}$ & H_14 \\
\hline SCY & MT 1 & EFA & 775 & $\sqrt{ }$ & ++ & ++ & -- & ++ & ++ & ++ & ++ & -- & & NA \\
\hline SCY & MT 1 & EFA & 777 & $\sqrt{ }$ & ++ & ++ & -- & ++ & ++ & ++ & -- & -- & & NA \\
\hline SCY & MT 2 & PEEP & 675 & $\sqrt{ }$ & ++ & ++ & +- & ++ & ++ & ++ & +- & +- & & H_1 \\
\hline SCY & MT 2 & PEEP & 676 & $\sqrt{ }$ & ++ & ++ & +- & ++ & ++ & +- & +- & +- & & H_2 \\
\hline SCY & MT 2 & PEEP & 706 & $\sqrt{ }$ & ++ & ++ & -- & ++ & +- & +- & ++ & +- & & H_1 \\
\hline SCY & MT 2 & PEEP & 708 & \multicolumn{10}{|l|}{ NA } & H_1 \\
\hline SCY & MT 2 & PEEP & 709 & $\sqrt{ }$ & ++ & ++ & -- & ++ & ++ & +- & +- & +- & & H_1 \\
\hline SCY & MT 2 & PEEP & 710 & $\sqrt{ }$ & ++ & ++ & -- & $\mathrm{h}$ & ++ & ++ & ++ & +- & & H_4 \\
\hline SCY & MT 2 & PEEP & 711 & $\sqrt{ }$ & ++ & ++ & -- & $\mathrm{h}$ & ++ & ++ & ++ & -- & & H_1 \\
\hline SCY & MT 2 & PEEP & 729 & $\sqrt{ }$ & ++ & ++ & -- & ++ & ++ & -- & ++ & -- & & NA \\
\hline SCY & MT 2 & PEEP & 730 & $\sqrt{ }$ & ++ & ++ & +- & ++ & ++ & ++ & ++ & +- & & NA \\
\hline SCY & MT 2 & PEEP & 736 & $\sqrt{ }$ & ++ & ++ & -- & ++ & ++ & ++ & ++ & +- & & H_1 \\
\hline SCY & MT 2 & REHM & 765 & $\sqrt{ }$ & ++ & ++ & -- & $\mathrm{h}$ & ++ & ++ & +- & -- & & H_1 \\
\hline SCY & MT 2 & ZBA & 634 & \multicolumn{10}{|l|}{$\mathrm{NA}$} & H_1 \\
\hline SCY & MT 2 & ZBA & 737 & $\sqrt{ }$ & ++ & ++ & -- & $\mathrm{h}$ & ++ & +- & +- & -- & & H_1 \\
\hline SCY & MT 2 & ZBA & 738 & $\sqrt{ }$ & ++ & +- & +- & ++ & ++ & $\mathrm{p}^{* *}$ & +- & -- & ${ }^{* *} \mathrm{~Pa} . \mathrm{Inv}$ & H_5 \\
\hline SCY & MT 2 & ZBA & 739 & $\sqrt{ }$ & ++ & ++ & -- & $\mathrm{h}$ & ++ & +- & +- & +- & & H_5 \\
\hline SCY & MT 2 & ZBA & 740 & \multicolumn{10}{|l|}{ NA } & H_5 \\
\hline SCY & MT 3 & PEEP & 674 & $\sqrt{ }$ & ++ & ++ & +- & ++ & ++ & ++ & ++ & +- & & H_1 \\
\hline SCY & MT 3 & PEEP & 698 & $\mathrm{P}^{*}$ & ++ & ++ & +- & ++ & ++ & -- & +- & +- & $\begin{array}{l}* 13 \& 16 \text { polymor- } \\
\text { phic }\end{array}$ & H_1 \\
\hline SCY & MT 3 & PEEP & 699 & $\sqrt{ }$ & ++ & ++ & -- & ++ & ++ & +- & ++ & +- & & H_1 \\
\hline SCY & MT 3 & REHM & 764 & $\sqrt{ }$ & ++ & ++ & -- & ++ & +- & ++ & +- & $\mathrm{P}^{* *}$ & ** Pa. Inv & H_8 \\
\hline SCY & MT 3 & REHM & 763 & $\sqrt{ }$ & ++ & ++ & -- & ++ & -- & ++ & +- & $\mathrm{P}^{* *}$ & ${ }^{* *} \mathrm{~Pa} . \mathrm{Inv}$ & NA \\
\hline SCY & MT 3 & ZBA & 733 & $\sqrt{ }$ & ++ & ++ & -- & ++ & ++ & -- & ++ & -- & & NA \\
\hline SCY & MT 3 & ZBA & 741 & \multicolumn{10}{|l|}{ NA } & H-6 \\
\hline NA & -- & ZBA & 414 & \multicolumn{10}{|l|}{ NA } & H_1 \\
\hline SNI & MT 4 & ZBA & 732 & $\sqrt{ }$ & ++ & ++ & -- & -- & $\mathrm{p}^{* *}$ & ++ & +- & -- & ${ }^{* *} \mathrm{~Pa} . \mathrm{Inv}$ & NA \\
\hline SNI & MT 4 & PEEP & 677 & $p^{*}$ & ++ & ++ & +- & -- & ++ & $\mathrm{p}^{* *}$ & +- & +- & $\begin{array}{l}{ }^{*} \text { Pe. Inv. } 13,{ }^{* *} \\
\text { Pa. Inv }\end{array}$ & $\mathrm{H} \_1$ \\
\hline SNI & MT 4 & PEEP & 687 & \multicolumn{10}{|l|}{ NA } & H_1 \\
\hline SNI & MT 4 & PEEP & 696 & $\sqrt{ }$ & ++ & ++ & ++ & -- & ++ & ++ & +- & -- & & H_1 \\
\hline SNI & MT 4 & PEEP & 707 & $\sqrt{ }$ & ++ & ++ & +- & -- & ++ & ++ & +- & +- & & H_1 \\
\hline SNI & MT 4 & PEEP & 712 & $\sqrt{ }$ & ++ & ++ & +- & -- & ++ & ++ & ++ & +- & & H_1 \\
\hline SNI & MT 4 & PEEP & 734 & \multicolumn{10}{|l|}{$\mathrm{NA}$} & H_1 \\
\hline SNI & MT 4 & PEEP & 735 & $\sqrt{ }$ & ++ & ++ & -- & -- & ++ & ++ & +- & +- & & H_1 \\
\hline SNI & MT 4 & PEEP & 697 & $\sqrt{ }$ & ++ & ++ & +- & -- & ++ & ++ & +- & -- & & H_3 \\
\hline SNI & MT 4 & RGO & 760 & NA & & & & & & & & & & H_7 \\
\hline
\end{tabular}

Table 2. Summary of morphological, karyological and molecular data obtained in the present study. $\sqrt{ }$, normal G-pattern; p, polymorphism; +-, presence/absence; h, size heteromorphism; NA, not available. Pe. Inv, pericentric inversion; Pa. Inv, paracentric inversion. Chromosomal data from Nieves et al., 2017. ¥ New analyzed individuals.

limit of this genus i.e. ${ }^{31,33,34,38}$. In this context, the present contribution was centered in characterizing captive specimens, some of them with unknown provenance, of putative Sapajus cay and Sapajus nigritus analyzing 


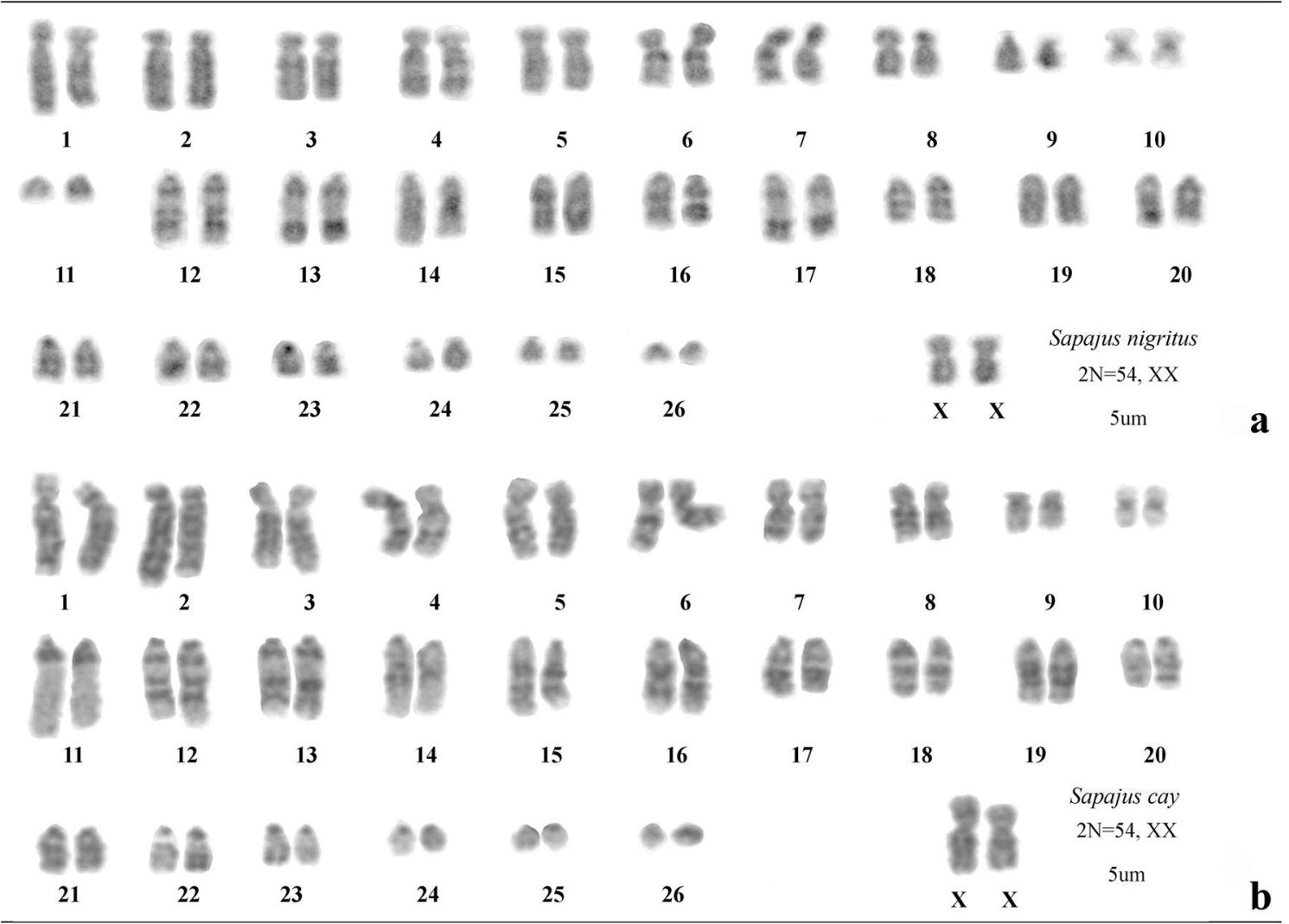

\section{(c-g)}
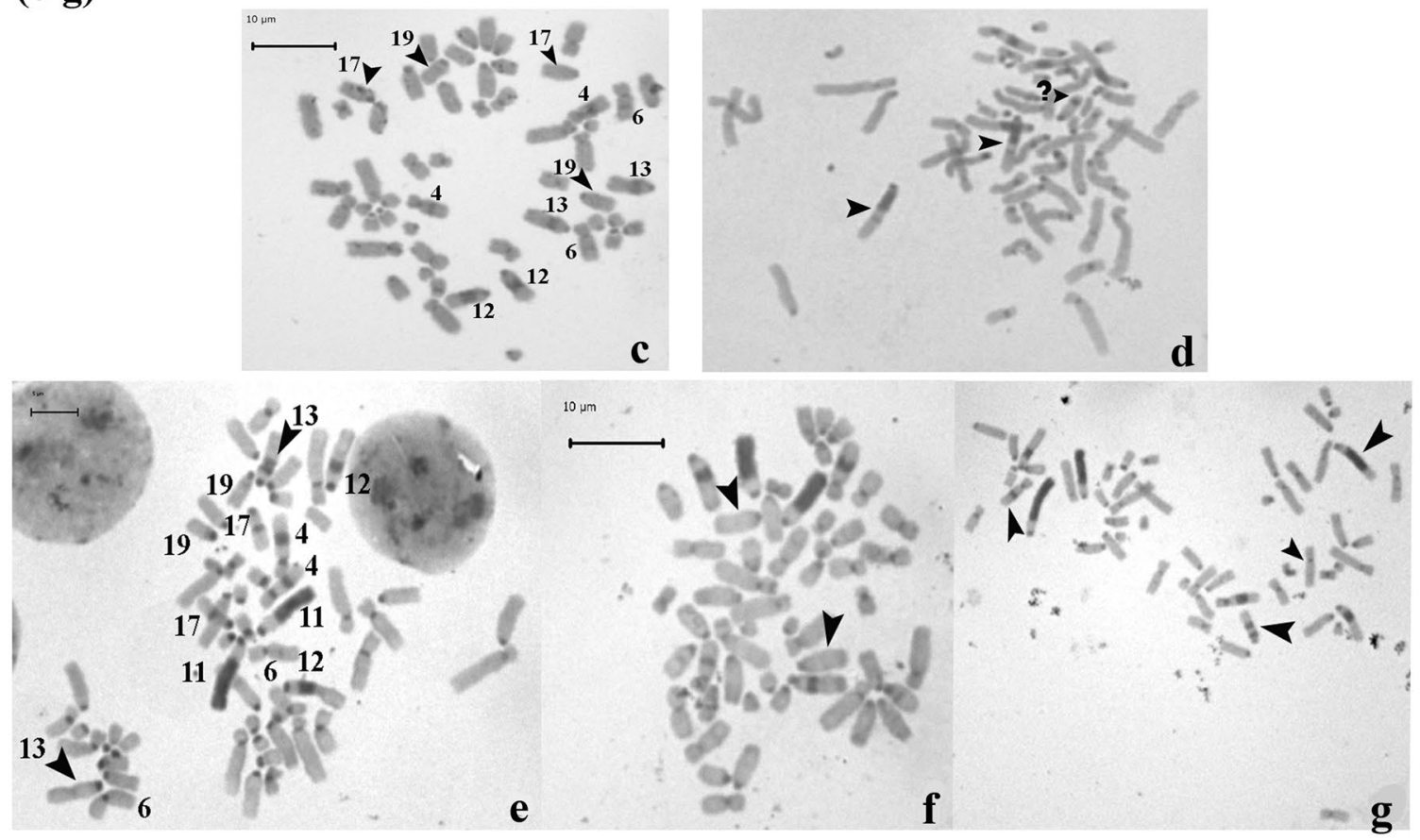

Figure 3. $\mathrm{G}$ and $\mathrm{C}$ banding patterns and polymorphisms found among the studied individuals. (a,b) G-banded patterns observed in SNI and SCY respectively. (c-g) C-banded metaphases illustrating different heterochromatin polymorphisms found in both species, highlighted with arrows. (c) Polymorphisms in chromosomal pairs \#13,17 and 19 of Sapajus nigritus and a paracentric inversion resulting in a new heterochromatic band. (d) (?) shows an undescribed band. (e-g) Polymorphism in chromosomal pair \#13 of Sapajus cay. 


\begin{tabular}{|c|c|c|c|c|c|}
\hline \multirow[b]{2}{*}{ Haplotype ID } & \multicolumn{4}{|l|}{ SCY } & \multirow{2}{*}{\begin{tabular}{|l} 
SNI \\
Morphotype 4
\end{tabular}} \\
\hline & \begin{tabular}{|l|} 
Morphotype1 \\
\end{tabular} & Morphotype 2 & Morphotype 3 & Not available Morphotype & \\
\hline H_1 & & 9 & 3 & 1 & 7 \\
\hline H_2 & & 1 & & & \\
\hline H_3 & & & & & 1 \\
\hline H_4 & & 1 & & & \\
\hline H_5 & & 2 & & & \\
\hline H_6 & & & 1 & & \\
\hline H_7 & & & & & 1 \\
\hline H_8 & & & 1 & & \\
\hline H_9 & 3 & & & & \\
\hline H_10 & 1 & & & & \\
\hline H_11 & 1 & & & & \\
\hline H_12 & 1 & & & & \\
\hline H_13 & 1 & & & & \\
\hline H_14 & 1 & & & & \\
\hline Haplotype diversity $(h)$ & $0.893 \pm 0.111$ & $0.571 \pm 0.132$ & $0.700 \pm 0.218$ & - & \\
\hline Nucleotide diversity $(\pi)$ & $0.015 \pm 0.009$ & $0.013 \pm 0.007$ & $0.0278 \pm 0.017$ & - & \\
\hline Haplotype diversity $(h)$ & $0.766 \pm 0.084$ & & & & $0.417 \pm 0.191$ \\
\hline Nucleotide diversity $(\pi)$ & $0.023 \pm 0.012$ & & & & $0.015 \pm 0.008$ \\
\hline
\end{tabular}

Table 3. Absolute haplotype frequencies and genetic diversity indices (haplotype diversity $(\mathrm{h})$ and nucleotide diversity $(\pi)$ ) with their standard deviation for SCY and SNI and for different morphotypes within SCY using mitochondrial DNA control region (mtDNA-CR) sequence data.

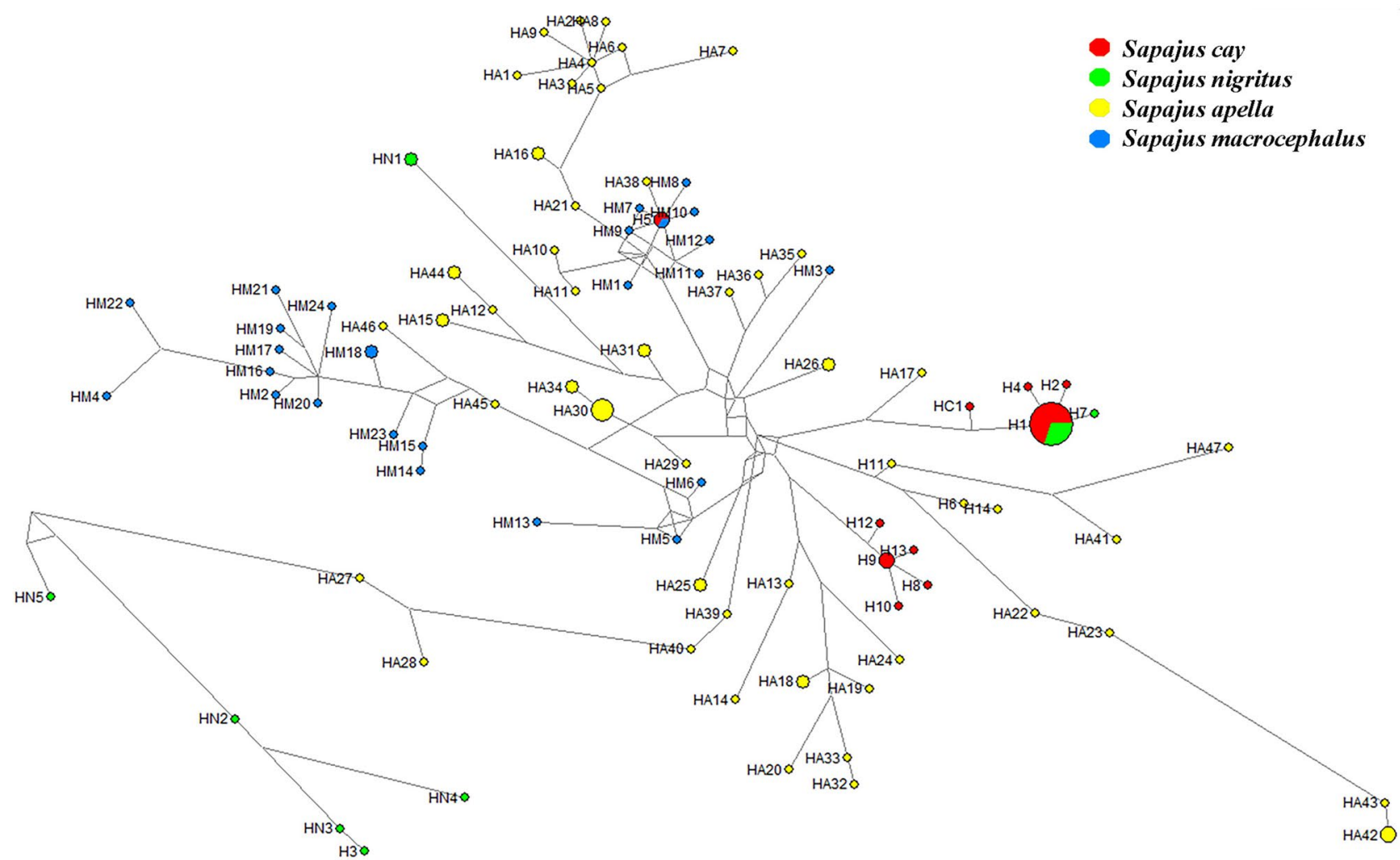

Figure 4. Median-joining haplotype network based on the $515 \mathrm{bp}$ mtDNA-CR sequence from 36 specimens of S. nigritus and S. cay and published available sequences from these species and other nearby capuchin species, S. apella and S. macrocephalus (namely $\mathrm{HC1}$ for S. cay, HN1-HN5 for S. nigritus, HA1-HA45 for S. apella and HM1-HM24 for S. macrocephalus see "Material and methods" section). The size of the circles (haplotypes) is proportional to the number of specimens sharing a given haplotype. Branches are proportional to the mutation number. Sapajus cay individuals' haplotypes are represented in red, S. nigritus ones in green, S. apella in yellow, and $S$. macrocephalus in blue. 
simultaneously molecular, chromosomal and morphological datasets as complementary sources to achieve a more accurate evaluation of their variability.

The presence of conspicuous heterochromatic blocks corresponding to repeated sequences distributed throughout the karyotype is a distinctive cytogenetic feature of capuchin monkeys. Previous results of Nieves et al. ${ }^{19}$ proposed that for SCY and SNI the most polymorphic chromosome pairs were \#6, 17 and 19: in SNI the highest frequencies were observed for pairs 17 and 6, while in SCY for pairs 6 and 17. Chromosome pair 19 showed a similar but lower percentage of heteromorphism in both species. Also, it was concluded that there was only a weak relationship between geographical origin and heterochromatin pattern at the intraspecific level. In the present contribution adding new individuals, reanalyzing the published data and considering the provenance of several samples (which was unknown in the previous study), it was showed new evidence to distinguish species and to characterize the centers, within species, in relation to extracentromeric heterochromatin distribution.

According with previous studies, the heterochromatin pattern observed in the biggest acrocentric pair (\#11) is a marker for taxonomic diagnosis in capuchin monkeys. All SCY individuals were characterized for the presence of the block of pair \#11 in double doses although some size heteromorphisms could be observed whereas SNI individuals did not exhibited the extracentromeric heterochromatin block. In general, karyotype differences based on heterochromatic blocks do not constitute reproductive barrier because heterozygotes for such blocks do not affect the fertility of the carriers ${ }^{39}$. In those cases, karyotype differentiation may accompany speciation rather than promote it. In addition, some common chromosome features detected within centers, i.e., SCY Individuals from Northwest EFA (Salta center), most of them from Salta (Argentina) or Bolivia, exhibited low level of chromosome polymorphisms. On the other hand, individuals from PEEP, some of them from Paraguay, exhibited high level of polymorphism. Similar results were observed in individuals from ZBA (Buenos Aires) and REHM (Tucuman) with unknown provenance although probably from several origins. In regard to SNI, in both centers ZBA and PEEP, the individuals exhibited similar and moderately polymorphic heterochromatin patterns.

The analysis of phenotype demonstrated that samples of Northwest SCY individuals with inferred and assigned origin in Bolivia and Salta (EFA) also exhibited phenotype homogeneity (all individuals corresponded to MT 1) whereas monkeys from PEEP, ZBA and REHM exhibited either of two morphotypes (i.e., MT 2 or 3). In regard to SNI, the comparison of our results with those obtained by ${ }^{26,27,40}$ revealed that only the SNI individuals studied here presented the phenotype blackish body pelage and a lighter face (MT4).

Recently, Penedo et al. ${ }^{26}$ studied 26 captive individuals belonging to Sapajus, in Rio de Janeiro, Brazil. By analyzing the C-banding patterns and their pelage coloration these authors classified the animals into at least four large classes. Interestingly, they found that each C-banding pattern was associated with at least two phenotypes concerning pelage coloration. In our sample of SCY, even considering the occurrence of three morphotypes and different levels of chromosomal polymorphisms, we were able to discriminate and assign each morphotype with the most frequent karyotype (Fig. 1 bar diagrams and MT pie charts). In regard to SNI, the comparison of our results with those obtained by ${ }^{26,27,40}$ revealed that only the SNI individuals studied here presented the phenotype blackish body pelage and a lighter face, and a karyotype in which chromosomal pair \#11 lacks the extracentromeric heterochromatin block described by ${ }^{28}$.

The results mentioned above may indicate higher phenotypic and karyotypic intra- and inter population variation in SNI from Brazil ${ }^{26}$ than from Argentina. A possible explanation may be related to the occurrence of polytypic populations of Brazilian SNI living in sympatry with a mixture of karyotypes and phenotypes in hybrid areas. Further studies involving a complete karyological characterization of SNI from their natural range in Brazil -especially populations close to Misiones province in Argentina, such as those in Santa Catarina, Paraná and Rio Grande do Sul- and a subsequent comparison with SNI from Argentina are needed to establish this point conclusively.

The analysis of the $515 \mathrm{bp}$ mtDNA-CR sequence revealed that the studied SCY individuals exhibited the highest level of genetic diversity in terms of haplotype and nucleotide diversity. This result may be explained by the fact that the samples identified as SCY comprised individuals from different geographic origins. The samples assigned to SNI, which included a smaller number of individuals whose putative geographical origin was restricted to a single province, showed lower levels of variability, with at least three haplotypes. Comparing the centers regarding haplotype diversity, EFA in the Northwest appeared as the most diverse (in contrast to what is observed at chromosome and morphology level), whereas PEEP, REHM and ZBA exhibited a low number of haplotypes but exhibited higher phenotype and chromosome variation. Current results pointed out that $\mathrm{H}_{-} 1$ was identified as the most frequent haplotype in both studied species and the reference samples of SCY.

The network constructed with haplotypes identified here and reference sequences showed some phylogeographic structure suggesting the existence of at least four groups of haplotypes with one of them (Group A) being the most frequent in the Northeastern Region of Argentina (NEA) and which include SCY and SNI individuals. Groups B and C were only observed in SCY individuals from the relatively closely located centers in Salta and Tucumán, suggesting that these haplotype groups may be representative of the Northwestern Region of Argentina (NOA). SCY Haplotypes from NOA exhibited major similarity with SAP from relatively near geographic area. Group D clustered haplotypes detected in SNI, one haplotype identified in PEEP (Misiones) (H_3) and several haplotypes described previously in Brazil (HN2, HN3, HN4, HN5). It is striking the position in the network of an isolated haplotype, H_5, belonging to two $S$. cay individuals from JZBA of unknown origin and one $S$. macrocephalus from literature. For this case, it could be proposed at least two hypotheses, (1) that those animals are hybrids between S. cay and S. macrocephalus, or (2) that they are indeed S. macrocephalus. However, to corroborate this second option, we do not have the $S$. macrocephalus karyotype as it has not been described (or at least it has not been published yet). Another isolated haplotype (HN1) in the network belonged to a sample which formerly was assigned to SNI but recently were reassigned to S. robustus ${ }^{9}$ explaining the divergence of sequences. HN2 haplotype corresponds to a sample which was also reassigned to $S$. robustus but maintain a clear relationship with SNI haplotypes. 
No previous information about Sapajus' mtDNA variation in north Argentina was reported up to date. Our analysis of $\mathrm{mt}$ DNA-CR of $S$. cay also showed two divergent groups: samples from NEA with assigned or probable origin in Paraguay, related to haplotype (HC) $)^{33}$ assigned to southern Mato Grosso (Brazil) and close to a S. apella haplotype (HA17) from northern Amazon; and individuals from NOA with assigned origin in Salta (Argentina) and Bolivia with high mitochondrial genetic diversity and more related to $S$. apella haplotypes from nearby regions than to the other $S$. cay groups. Some studies based on sequence data for other genes (Cyt $\mathrm{b}$ and COI genes), described mt DNA variation of $S$. cay from Southeastern Paraguay and Mato Grosso do Sul (south, east, west and south-west) (Brazil) ${ }^{9,33}$. Further studies must consider approaches using the same mtDNA marker and examining all localities where $S$. cay was detected to get a better knowledge about mtDNA genetic variability in this species.

Three haplotypes were detected in SNI: H_1, identified also in samples of SCY from our analysis and previous ones; $\mathrm{H} \_7$, a haplotype very close to $\mathrm{H} \_1$ and; $\mathrm{H} \_3$, a very divergent haplotype that was not identified until now and very close to SNI haplotypes previously detected. The existence of zones of contact between both species suggests that hybridization may have been frequent during the evolution of the lineages ${ }^{9,10}$. With our new finding in mind, one is tempted to propose that individuals identified as SNI can be hybrids between both species analyzed here. Still, our results revealed that all individuals identified as SNI exhibited the same karyotype and morphotype. One likely scenario to explain our results may be related with a past hybridization event occurred many generations ago and this event is still retained in mt DNA SNI samples from the present study as was proposed for macaques ${ }^{41}$. However, this hypothesis rests on very low number of samples. It is necessary to perform a wider analysis involving chromosome, phenotype and molecular approaches to gain deeper in sight into the variability in this taxon.

The present study constitutes the first description of mtDNA-CR in SCY and SNI individuals at the southernmost distribution limit of the genus. A trend toward greater nucleotide variability for SCY than for SNI was observed in our limited sample. Likewise, cytogenetic variability was higher for SCY than for SNI in terms of polymorphisms for extracentromeric heterochromatin and for structural rearrangements. In the case of SNI, more studies are needed to conclusively determine the level of genetic diversity and population structure. We recognize the need for new morphological, chromosomal, and molecular analyses for subsampled and unexplored geographic regions of both species distributions to improve our knowledge about intraspecific and interspecific variation.

The analysis of the mtDNA-CR made in our study proved to be an important tool for an accurate identification of species belonging to genus Sapajus, and useful for both in situ and ex situ management. In general terms, under captivity conditions, it seems advisable to group together animals with similar polymorphisms at the chromosomal and mtDNA-CR levels, since they may come from the same population.

\section{Conclusions}

- The present study constitutes the first description of mtDNA-CR in SCY and SNI individuals at the southernmost distribution limit of the genus.

- A phylogeographic approach distinguished mtDNA lineages of $S$. cay from northwestern and northeastern Argentina

- The analysis of the mtDNA-CR made in the present phenotypic and genetic study proved to be an important tool for the accurate identification of species belonging to genus Sapajus, and useful for both in situ and ex situ management.

\section{Material and methods}

All animal work was approved by the Ethical Committee of the Argentine Society for the study of Mammals (SAREM).

The study was carried out in compliance with the ARRIVE guidelines (https://arriveguidelines.org).

Animal housing and management. Capuchins were housed in five Institutions located in the northwest (REHM and EFA), northeast (PEEP and RGO) and center-east (ZBA in the capital city) of Argentina (Table 1), where they were maintained in compliance with local regulations. Such institutions were zoos and/or rescue centers for animals confiscated from illegal trafficking and possession. Except for the EFA, they were opened to the public for visiting. The enclosures differed according to the general collection plan of the institutions. In REHM, EFA, PEEP and RGO, animals were kept in outdoor wire-mesh enclosures with soil floor and a roof, while in ZBA they were in an open enclosure located on a large island surrounded by moat of water and provided with several shelters. In the institutions where individuals of both species were found, PEEP and ZBA, they were always housed in separate enclosures, following the phenotypic description of ${ }^{1,13}$ for their separation. In all the institutions, newly arrived animals were isolated in a quarantine area for 10-20 days and then transferred to an enclosure close to the established collection, thus allowing for a gradual transition. In general, primates were grouped according to their age, size of the resident troop and size of the enclosure. They were fed at least once daily a balanced and varied diet containing seasonal fruits, vegetables and seeds, and red and white meats. Water was available ad libitum. Drinkers and feeders were cleaned and disinfected daily and enclosures at least every other day. Vitamin supplementation was performed at least once a week and deworming at least every six months. Animals were provided environmental and behavioral enrichment (with social, occupational, motor and sensory stimuli) based on their biological and behavioral requirements. General health status was sporadically assessed by veterinarians through the analysis of feces, urine and blood. 
To obtain the blood samples used in our study, the veterinarians of each institution sedated the animals with Ketamine in their enclosures and then transferred them to the operation room, where they were placed on a stretcher and were administered maintenance anesthesia. After collection procedures, the animals were monitored until complete anesthetic recovery. The accommodation and maintenance of the individuals followed the welfare standards proposed by the code of ethics of ALPZA and WAZA (Latin American Zoo and Aquarium Association, 2018, https://www.alpza.com/herramientas; World Association of Zoos and Aquariums, 2018, http:// www.waza.org/en/site/conservation/code-of-ethics-and-animal-welfare). The well-being and survival of all the specimens involved in this study represented a high priority and therefore euthanasia was not carried out.

Phenotypic diagnosis. The different pelage coloration patterns and its variation among the individuals studied were analyzed based on data from Nieves and Mudry ${ }^{37}$ and re-evaluated (Table 2). Each specimen was photographed and assigned to either one of the two suspected species based on external characteristics, according to ${ }^{1,13}$ as follows:

SNI (black capuchin): It has a very dark brown or gray, even blackish, pelage; with no (or very vague) dorsal stripe, the face is white and contrasts with the color of the body. The sideburns are poorly distinct; the limbs are darker than the body, usually blackish, presence of tufts on the crown, which are pointed in adults but become worn away with age.

SCY (yellow-bearded capuchin): It has a yellow to white head with black crown and sideburns, which contrast with the light-colored body; presence of a prominent dark dorsal stripe; limbs mainly dark to blackish; upper arms not lighter than body; the underside is yellowish or reddish, often overlaid with black.

Blood sample collection. Whole blood samples were collected from 44 captive individuals held in five Argentinean centers (Table 1; Fig. 1). After anesthetizing animals with ketamine ( $2 \mathrm{mg} / \mathrm{kg}$ weight), 2-5 ml of whole blood were obtained by venipuncture with disposable syringes and then transferred into two sterile tubes, one containing heparin (Sobrius, 500UI/ml) for cytogenetic studies, and the other EDTA (5\% w/v) for molecular analyses.

Karyological diagnosis. The patterns of chromosome variation were analyzed using the observations of the present work and data from previous studies (Table 2). To confirm the species status of each specimen, cultures of peripheral blood lymphocytes were used to apply G- and C-banding following ${ }^{42}$.

After the implementation of the C-banding protocol, at least 10 mitotic metaphases were analyzed per individual, with a particular focus on chromosome pairs having extracentromeric heterochromatin blocks and possessing structural rearrangements i.e. \#4, 6, 11, 12, 13, 17, and 19.

The banding patterns thus obtained were compared with those already reported in the literature for Cebus and Sapajus spp.: Cebus albifrons ${ }^{43}$; S. apella ${ }^{44}$; C. capucinus ${ }^{45}$; C. paraguayanus (S. cay) ${ }^{12}$; S. nigritus ${ }^{28}$; C. nigrivitattus (C. olivaceus) $^{46}$; and S. xanthosternos ${ }^{47}$.

Molecular analyses. DNA extraction was carried out following ${ }^{48}$. For the amplification of the mtDNA-CR a new primer pair was designed using the Primer3 v. 0.4.0 software ${ }^{49}$. In addition, a sequence from a SNI sample previously obtained with the universal primer pair developed by ${ }^{50}$ (data not shown) was used: LD: CNI555 5'-GGCATACACAATTCTTTTCCTA-3' and HD: CNI555 5'-ACCCTATGCATCCAGTGACG-3'. Polymerase chain reaction (PCR) amplifications were carried out in a 9600 Perkin Elmer thermocycler under the following conditions: 30 cycles of $93^{\circ} \mathrm{C}$ for $1 \mathrm{~min}, 60^{\circ} \mathrm{C}$ for $1 \mathrm{~min}$, and $72^{\circ} \mathrm{C}$ for $3 \mathrm{~min}$. PCR reactions were performed in a final volume of $25 \mu \mathrm{l}$ containing $2 \mu \mathrm{l}$ of DNA template (100-150 ng), $1 \times$ PCR buffer with (NH4) ${ }_{2} \mathrm{SO} 4$ (Fermentas), $1.5 \mathrm{mM}$ of $\mathrm{MgCl}_{2}, 0.2 \mu \mathrm{M}$ of each primer; $0.2 \mathrm{mM}$ of each dNTP; and $0.5 \mathrm{U}$ Taq polymerase (Fermentas). The PCR products were electrophoresed in $2 \%$ agarose gel with $0.5 \mathrm{ug} / \mathrm{ml}$ of Ethidium Bromide (BIO-RAD) and visualized by an ultraviolet transilluminator. For each analyzed individual, forward and reverse nucleotide sequences were obtained by capillary electrophoresis using the sequencing facility of the Department of Ecology, Genetics and Evolution, FCEyN, University of Buenos Aires. Sequences were aligned and edited using BioEdit v.7.0.5. $3^{51}$ and Clustal X v.1.8 $8^{52}$. Variable nucleotide sites and haplotypes were identified using GenAlEx v.6.1 $1^{53}$. Arlequin v3.1 $1^{54}$ was used for computing estimates of nucleotide diversity $(\pi)$ and haplotype diversity (h) according to ${ }^{55}$.

To determine the mtDNA-CR diversity of $S$. cay and $S$. nigritus in a broad context, we included the sequences from Argentina analyzed herein and the GenBank reference sequences of these species from Paraguay and Brazil. We used the following reference accession numbers: MF472524, MF472525 ${ }^{31}$, KX592678 ${ }^{32}$ and KY $173186^{33}$ for the analysis of SCY; and KY173226, KY173227, KY173230 33,34 , MF472523, MF472522 $2^{31}$ and KX592680 ${ }^{32}$, for the analysis of SNI. Although the sequence KX592678 is 14 bp shorter than the 515-bp fragment analyzed here, it was included because there are no variable nucleotide sites in the missing portion. Finally, we excluded the sequence JQ317617 from ${ }^{56}$ because it is 52 bp shorter than the analyzed 515 bp-fragment and the missing portion contains variable sites.

Haplotype relationships were estimated using the sequences of $S$. cay and S. nigritus mentioned above and the GenBank reference sequences (which include the same DNA fragment analyzed here) from other nearby capuchin species, S. apella and S. macrocephalus. We considered the reference accession numbers KX756240.1, KX592677.132; KY173143.1-KY173160.1, KY173162.1-KY173184.1 ${ }^{33}$; MF472455.1-MFA72470.1, MF472483.1, MFA472499.1, MF472512.1-MFA472513.19 for S. apella and KX592679.1 ${ }^{32}$; KY173200.1-KY173213.1, KY173215.1-KY173225.1 ${ }^{33}$ for S. macrocephalus. 
Sequence alignments were performed with BLAST $^{57}$ and a median joining network (MJN) implemented in NETWORK 5.0.1.1 ${ }^{58}$ was constructed.

Received: 21 August 2020; Accepted: 19 March 2021

Published online: 31 March 2021

\section{References}

1. Cabrera, A. Catálogo de los Mamíferos Sudamericanos. Rev. Mus. Arg. Cs. Nat. (Zool.) IV, 1-732 (1957).

2. Wilson, D. E. \& Reeder, D. M. Mammal Species of the World: A Taxonomic and Geographic Reference 3rd edn. (Johns Hopkins University Press, 2005).

3. Madden, M. et al. Modelling the monkey habitat in Brazil. Geospat. Today 5, 26-35 (2007)

4. Hershkovitz, P. Mammals of northern Colombia. Preliminary report No. 4: Monkeys (Primates), with taxonomic revisions of some forms. Proc. US Nat. Mus. 98, 323-427 (1949).

5. Hill, W. C. O. Primates: Comparative Anatomy and Taxonomy. Vol. VI Cebidae, Part A. (Edinburgh University Press, 1960).

6. Assumpçao, C. An Ecological Study of the Primates of Southeastern Brazil with a Reappraisal of Cebus apella Races. Dissertation (University of Edinburgh at South Bridge, 1983).

7. Silva Jr, J. Especiacion nos macacos-prego e caiararas, gênero Cebus Erxleben, 1777 (Primates, Cebidae). Dissertation (Universidade Federal do Rio de Janeiro, 2001).

8. Rylands, A. B., Mittermeier, R. A. \& Silva, J. Jr. Neotropical primates: taxonomy and recently described species and subspecies. Int. Zoo Yearb. 46, 11-24 (2012).

9. Martins-Jr, A. M. G., Carneiro, J. C., Sampaio, I., Ferrari, S. F. \& Schneider, H. Phylogenetic relationships among Capuchin (Cebidae, Platyrrhini) lineages: an old event of sympatry explains the current distribution of Cebus and Sapajus. Genet. Mol. Biol. 41, 699-712 (2018).

10. Lynch-Alfaro, J. W. et al. Explosive Pleistocene range expansion leads to widespread Amazonian sympatry between robust and Gracile Capuchin Monkeys. J. Biogeogr. 39, 272-288 (2012).

11. Lynch-Alfaro, J. W., Silva-Jr, J. D. S. \& Rylands, A. B. How different are robust and gracile capuchin monkeys? An argument for the use of Sapajus and Cebus. Am. J. Primatol. 74, 273-286 (2012).

12. Matayoshi, T. et al. Chromosome studies in Cebus apella: the standard karyotype of Cebus apella paraguayanus Fisher, 1829. Am. J. Primatol. 10, 185-193 (1986).

13. Groves, C. P. Primate Taxonomy (Smithsonian Institution Press, 2001).

14. Martínez, R. A. et al. Parameters modeling speciogenic processes in Cebus apella (Primates: Platyrrhini) from Argentina. Mastozool. Neotrop. 9, 171-186 (2002).

15. Seuánez, H. N., Bonvicino, C. R. \& Moreira, M. A. M. The primates of the Neotropics: genomes and chromosomes. Cytogenet. Genome Res. 108, 38-46 (2005).

16. Amaral, P. J. S. et al. Phylogenetic studies of the genus Cebus (Cebidae-Primates) using chromosome painting and G-banding. BMC Evol. Biol. 8, 169 (2008).

17. Casado, F. et al. Mitochondrial divergence between 2 populations of the Hooded Capuchin, Cebus (Sapajus) cay (Platyrrhini, Primates). J. Hered. 101, 261-269 (2010).

18. Ruiz-García, M., Castillo, M. I. \& Luengas-Villamil, K. It is misleading to use Sapajus (robust capuchins) as a genus? A review of the evolution of the capuchins and suggestions on their systematics. In Molecular Population Genetics, Evolutionary Biology and Biological Conservation of Neotropical Primates (eds Ruiz-García, M. \& Shoshtell, J.) 209-268 (Nova Science Publishers, 2016).

19. Nieves, M., Fantini, L. \& Mudry, M. D. What do we know about the heterochromatin of capuchin monkeys (Cebus, Platyrrhini)?. Biol. J. Linn. Soc. 123, 113-124 (2017).

20. Rimoli, J. et al. Sapajus cay. The IUCN Red List of Threatened Species. e T136366A70612310 (2018). https://doi.org/10.2305/ IUCN.UK.2018-2.RLTS.T136366A70612310.en. Downloaded on 08 July 2020.

21. Martins, J. N. et al. Sapajus nigritus. The IUCN Red List of Threatened Species 2019: e.T136717A70614508 (2019). https://doi.org/ 10.2305/IUCN.UK.2019-3.RLTS.T136717A70614508.en. Downloaded on 07 July 2020.

22. Lynch-Alfaro, J. W., Izar, P. \& Ferreira, R. G. Capuchin monkey research priorities and urgent issues. Am. J. Primatol. 76, 705-720 (2014).

23. Martínez, R. A. et al. Genetic variability in two captive colonies of Cebus apella paraguayanus (Primates: Platyrrhini) from eastern Paraguay. Caryologia 57, 332-336 (2004).

24. Nieves, M., Mendez, G., Ortiz, A., Mühlmann, M. C. \& Mudry, M. D. Karyological diagnosis of Cebus (Primates: Platyrrhini) in captivity: detection of hybrids and management programs applications. Anim. Reprod. Sci. 108, 66-78 (2008).

25. Nieves, M. et al. Analysis of the heterochromatin of Cebus (Primates, Platyrrhini) by micro-FISH and banding pattern comparisons. J. Genet. 90, 111-117 (2011).

26. Penedo, D. M. et al. C-banding patterns and phenotypic characteristics in individuals of Sapajus (Primates: Platyrrhini) and its application to management in captivity. Caryologia 67, 314-320 (2014).

27. Matayoshi, T. et al. Heterochromatic variation in Cebus apella (Cebidae, Platyrrhini) of different geographic regions. Cytogenet. Cell Genet. 44, 158-162 (1987).

28. Mudry, M. D., Slavutsky, I., Zunino, G. E., Delprat, A. \& Brown, A. D. A new karyotype of Cebus apella from Argentina. Rev. Bras. Genet. 14, 729-738 (1991).

29. Bi, X. et al. The complete mitochondrial genome sequence of the black-capped capuchin (Cebus apella). Genet. Mol. Biol. 35, 545-552 (2012).

30. Finstermeier, K. et al. Mitogenomic phylogeny of living primates. PLoS ONE 8, e69504 (2013).

31. Martins-Jr, A. M. G. et al. Alu elements and the phylogeny of capuchin (Cebus and Sapajus) monkeys. Am. J. Primatol. 77, 368-375 (2015).

32. Lucarelli, M. et al. Polymorphism of the $3^{\prime}$-UTR of the dopamine transporter gene (DAT) in New World monkeys. Primates 58, 169-178 (2017).

33. Lima, M. G. M. et al. Capuchin monkey biogeography: understanding Sapajus Pleistocene range expansion and the current sympatry between Cebus and Sapajus. J. Biogeogr. 44, 810-820 (2017).

34. Lima, M. G. M. et al. A phylogenomic perspective on the robust capuchin monkey (Sapajus) radiation: first evidence for extensive population admixture across South America. Mol. Phylogenet. Evol. 124, 137-150 (2018).

35. Ascunce, M. S., Hasson, E., Mulligan, C. J. \& Mudry, M. D. Mitochondrial sequence diversity of the southernmost extant New World monkey, Alouatta caraya. Mol. Phyl. Evol. 43, 202-215 (2007).

36. Dunn, J. C. et al. Limited genetic diversity in the critically endangered Mexican howler monkey (Alouatta palliatae mexicana) in the Selva Zoque, Mexico. Primates https://doi.org/10.1007/s10329-013-0399-6 (2013). 
37. Nieves, M. \& Mudry, M. D. Diversity of Cebus species from the southern distribution of the genus. In Molecular Population Genetics, Evolutionary Biology and Biological Conservation of Neotropical Primates (eds Ruiz-García, M. \& Shoshtell, J.) 115-134 (Nova Science Publishers, 2016).

38. Nascimento, F., Lazar, A., Seuánez, H. N. \& Bonvicino, C. Reanalysis of the biogeographical hypothesis of range expansion between robust and gracile capuchin monkeys. J Biogeogr 42, 1349-1363 (2015).

39. King, M. Species Evolution. The Role of Chromosome Change (Cambridge University Press, 1993).

40. Vieira, A. G. \& de Oliveira, L. Levantamento dos fenótipos de Sapajus nigritus (Goldfuss, 1809) no Parque ecológico da cidade da criança de Presidente Prudente-SP. Agrar. Acad. Centro Científico Conhecer-Goiânia 1, 90 (2014).

41. Tosi, A. J., Morales, J. C. \& Melnick, D. J. Comparison of Y chromosome and mtDNA Phylogenies leads to unique inferences of macaque evolutionary history. Mol. Phylog. Evol. 17(2), 133-144 (2000).

42. Steinberg, E. R., Nieves, M., Fantini, L. \& Mudry, M. D. Primates karyological diagnosis and management programs applications. J. Med. Primatol. 43, 455-467 (2014).

43. García, M., Freitas, L., Miró, R. \& Egòzcue, J. Banding patterns of the chromosomes of Cebus albifrons. Comparative studies with Cebus apella. Folia Primatol. 25, 313-319 (1976).

44. García, M., Miró, R., Freitas, L. \& Egòzcue, J. Banding patterns of the chromosomes of Cebus apella: unstable chromosomes and pericentric inversion. Folia Primatol. 29, 196-205 (1978).

45. Dutrillaux, B., Couturier, J., Viegas-Pequignot, E., Chauvier, G. \& Trebbau, P. Presence d'une heterochromatine abondante dans le caryotype de deux Cebus: C. capucinus et C. nigrivittatus. Ann. Génét. 21, 142-148 (1978).

46. Martínez, R. A., Aguilera, M. \& Ferreira, C. The karyotype and C-banding of Cebus nigrivittatus from the Coastal Cordillera, Venezuela. Folia Primatol. 70, 37-40 (1999).

47. Seuánez, H. N. et al. Intraspecific chromosome variation in Cebus apella (Cebidae, Platyrrhini): the chromosomes of the yellow breasted capuchin Cebus apella xanthosternos Wied, 1820. Am. J. Primatol. 10, 237-247 (1986).

48. Corach, D., Penacino, G. \& Sala, A. Cadaveric DNA extraction protocol based on Cetyl Trimethyl Ammonium Bromide (CTAB). In Acta Medicinae Legalis XLIV (eds. Mangin, P. \& Ludes, B.) 35-36 (Springer, 1995).

49. Koressaar, T. \& Remm, M. Enhancements and modifications of primer design program Primer3. Bioinformatics 23, 1289-1291 (2007).

50. Kocher, T. D. et al. Dynamics of mitochondrial DNA evolution in animals: amplification and sequencing with conserved primers. Proc. Nat. Acad. Sc. USA 86, 6196-6200 (1989).

51. Hall, T. A. BioEdit: a user-friendly biological sequence alignment editor and analysis program for Windows 95/98/NT. Nucleic Acids Symp. Ser. 41, 95-98 (1999).

52. Higgins, D. G. \& Sharp, P. M. CLUSTAL: a package for performing multiple sequence alignment on a microcomputer. Gene 73, 237-244 (1988).

53. Peakall, R. \& Smouse, P. E. GENALEX 6: genetic analysis in Excel. Population genetic software for teaching and research. Mol. Ecol. Notes (Electronic) 6, 288-295 (2006).

54. Excoffier, L., Laval, G. \& Schneider, S. Arlequin ver 3.0: an integrated software package for population genetics data analysis. Evol. Bioinform. Online 1, 47-50 (2005).

55. Nei, M. Molecular Evolutionary Genetics (Columbia University Press, 1987).

56. Boubli, J. P., Rylands, A. B., Farias, I. P., Alfaro, M. E. \& Lynch-Alfaro, J. W. Cebus phylogenetic relationships: a preliminary reassessment of the diversity of the untufted capuchin monkeys. Am. J. Primatol. 74, 381-393 (2012).

57. Zhang, Z., Schwartz, L., Wagner, L. \& Miller, W. A greedy algorithm for aligning DNA sequence. J. Computat. Biol. 7, 203-214 (2000).

58. Bandelt, H. J., Forster, P. \& Röhl, A. Median-joining networks for inferring intraspecific phylogenies. Mol. Biol. Evol. 16, 37-48 (1999).

59. Arístide, L., Soto, I. M., Mudry, M. D. \& Nieves, M. Intra and interspecific variation in cranial morphology on the southernmost distributed Cebus (Platyrrhini, Primates) Species. J. Mammal. Evol. https://doi.org/10.1007/s10914-013-9249-y (2013).

60. Nieves, M., et al. Sapajus cay. In Categorización 2019 de los mamiferos de Argentina según su riesgo de extinción. Lista Roja de los mamiferos de Argentina. Versión digital (eds SAyDS-SAREM). http://cma.sarem.org.ar (2019).

\section{Acknowledgements}

The present work was supported by Consejo Nacional de Investigaciones Científicas y Técnicas (CONICET) Project PIP 0744 and Universidad de Buenos Aires Ciencia y Tecnología grants (UBACyT) Project X154 to MDM; and CONICET-AVG to MN. We thank the Ministerio de Ecología y Recursos Naturales Renovables (MEyRNR), Parque Ecológico El Puma (PEEP), the owners of the Güira Oga Private Reserve (RGO) in Misiones Province, the Estación de Fauna Autóctona (EFA) in Salta and the Buenos Aires Zoo (ZBA) for issuing permits for access to the institutions and transportation of samples. We are particularly grateful to the trained veterinarians for animal handling, anesthesia administration and blood sample collection. We are indebted to CONICET for a postgraduate fellowship to DLH. All animal work followed the Guidelines of the Ethical Committee of the Argentine Society of Mammalian Studies (SAREM). The authors also adhered to the guide for Care and Use of Experimental Animals, as promulgated by the American Society of Primatologists (ASP) Principles for the Ethical Treatment of Non-human Primates.

\section{Author contributions}

M.N.: Conceptualization, supervision, writing—review and editing. M.I.R.: Formal analysis, writing-review and editing. C.S.: Writing-review and editing. D.L.H.: Investigation, writing-original draft. C.F.A.: Conceptualization, resources, writing - original draft and review. M.D.M.: project administration, founding acquisition, writing -review and editing.

\section{Competing interests}

The authors declare no competing interests.

\section{Additional information}

Supplementary information The online version contains supplementary material available at https://doi.org/ 10.1038/s41598-021-86734-w.

Correspondence and requests for materials should be addressed to M.N. 
Reprints and permissions information is available at www.nature.com/reprints.

Publisher's note Springer Nature remains neutral with regard to jurisdictional claims in published maps and institutional affiliations.

(c) (i) Open Access This article is licensed under a Creative Commons Attribution 4.0 International License, which permits use, sharing, adaptation, distribution and reproduction in any medium or format, as long as you give appropriate credit to the original author(s) and the source, provide a link to the Creative Commons licence, and indicate if changes were made. The images or other third party material in this article are included in the article's Creative Commons licence, unless indicated otherwise in a credit line to the material. If material is not included in the article's Creative Commons licence and your intended use is not permitted by statutory regulation or exceeds the permitted use, you will need to obtain permission directly from the copyright holder. To view a copy of this licence, visit http://creativecommons.org/licenses/by/4.0/.

(C) The Author(s) 2021 